\title{
Editorial
}

\section{Challenges of Asian Models and Values for Sustainable Development}

\author{
Yongrok Choi \\ Department of International Trade, Inha University, 100 Inha-ro, Nam-gu, Incheon 402-751, Korea; \\ yrchoi@inha.ac.kr; Tel.: +82-032-860-7760; Fax: +82-32-866-6877
}

Received: 4 March 2019; Accepted: 8 March 2019; Published: 12 March 2019

check for updates

\begin{abstract}
Northeast Asia is one of the most dynamic regions in the global economy in its dynamic change in the economic scape as well as in the challenge of environmental issues. In particular, many countries in Asia have experienced transitional challenges from a quantitative, GDP-oriented economic development toward environmental-friendly, sustainable development. The quality of the life became much more important for government policies, also fueled by the demand from the private sector. Nonetheless, these countries are experiencing much more severe and sarcastic skepticism in response to government policies, resulting in a lack of effective governance. The Sustainable Asia Conference (SAC) has promoted the importance of these challenges for 10 years since its inauguration in 2009. The major consensus on sustainable development reached at the conference may come from innovation in the positive-sum game approach to environmentally friendly development and sustainable governance in order for the initial innovation to be put into effect. Moreover, due to the complicated and complex process of solving environmental challenges, the countries in this region should cooperate with strong partnerships as well as open connectivity. Therefore, all the countries should participate in the project not as helpers, but as partners to create and share value through regional cooperation.
\end{abstract}

Keywords: sustainable development; Sustainable Asia Conference; Asian value; governance

\section{Introduction}

Each winter, northeast Asian countries have been experiencing ever-worsening air pollution brought by winds. Such pollution is caused by many seasonal factors, such as the traditional heating system in northern Chinese provinces. Since there is always the seasonal wind from northwest Asia traveling toward Japan via South Korea (hereinafter referred to as Korea), the polluted wind affects the entirety of this region. Moreover, since northeast Asian countries comprise the most rapidly changing region in the world economy, the challenges in the region raised by air pollution issues are so serious not only for the immediate region, but also for the sustainable development of the global economy [1]. Unfortunately, sustainable development requires proactive participation by the public and private sectors in diverse fields of activity, due to the complicated and complex procedures necessary to achieve better performance. Northeast Asian countries are in a transition period going from quantitative economic development toward a qualitative, healthier advanced economy; thus, strong leadership by governments is demanded by the private sector [2].

On the transition toward a healthier social life, it is of utmost importance to develop an Asian model to solve the sustainable development and sustainable management issues in more harmonized ways and from the perspectives of Asian oriental cultures. Otherwise, efforts to change may result in superficial, one-time-only successes, meaning a lack of sustainable governance. In order to promote sustainable governance as well as environmentally friendly, sustainable development, public and private partnerships (PPPs) should incorporate the cultural background. To date, most research on 
this region is focused on the application of market-oriented 'western-style' approaches in developed countries-such as the Porter hypothesis or the Kuznets curve, etc. [3-5]. However, these approaches may not be effective for developing countries such as Korea and China due to their cultural backgrounds and historical experiences [1]. Rather, government-led political regulation could be much more effective in northeast Asia. Therefore, in this study we aim to address the new challenges of creating an Asian model, and create a basic platform of Asian values that can be employed in the movement toward sustainable development $[1,5]$.

As one of the best examples, 4 years ago, Beijing was faced with an impossible mission-to clear the heavy air pollution during the winter season. It was so clear with fresh air that most people in Beijing could not believe it happened! This winter miracle was attributed to the strong leadership by the Chinese government. To emphasize the importance of ecological civilization, the Chinese government appointed the ex-Minister of Environment as the mayor of Beijing and put a lot of strong regulations on the transportation, heating systems, etc., which is totally different from the market-oriented western approach. However, this could not be repeated due to the current lack of governance, resulting from the lack of private participation. Here, governance is defined as the workable mechanism for sustainable performance [2]. The leadership of the government in northeast Asian countries is so important to initiate new challenges for the future; however, for good governance, it government leadership needs to be harmonized with PPPs based on the relevant cultural background [1]. The basic motivation for this special issue was to determine the optimal path toward the sustainable development of the region, based on the voluntary participation and cooperation between public and private sectors to promote innovation. Innovation, by nature, is not sustainable without the support of all partners. Unfortunately, the traditional regime will not lead to sustainable development, because it is based on the development of competitive solutions-even for environmental issues $[5,6]$. Therefore, instead of a competition-based approach for environmental issues, a sustainable method with all the parties involved in positive-sum approach is needed to continuously promote sustainable innovation.

This Special Issue consists of selected papers from the Sustainable Asia Conference (SAC) 2018, an annual international conference held at the Chinese Academy of Science (CAS), Beijing, China, 18-21 May 2018. SAC (http://abf.inha.ac.kr/) is one of the leading international conferences for sharing novel and fundamental advances in sustainable development in Asia. In this Special Issue, we highlight feasible ways toward achieving an advanced, healthier quality of life based on Asian values and Asian cultural perspectives.

\section{Innovation for Good Governance}

Since the traditional approach is based on the competitive maximization proposed by Adam Smith's invisible hand, most market-oriented approaches in advanced economies emphasize higher productivity or efficiency under environmental constraints. Unfortunately, it is not easy to determine how to harmonize the combination of economic development and environmental protection via a competitive solution approach. In most developing countries, therefore, the focus is placed on achieving a higher GDP, with only decorative or superficial slogans only dedicated to the environmental challenges. Nonetheless, northeast Asian countries are severely suffering due to air pollution, especially in the winter season, and thus these countries cannot get away with only making slogans to combat environmental issues. Instead, they should transform their economies to work toward environmental protection and sustainable development [7]. In China, millions of people die directly or indirectly due to the heavy particulate matter (PM), a main component of air pollution [8]. The situation is the same in Korea. Korea had noticed the serious air pollution in Beijing, but was not faced with the same air pollution problem until recently. Now all northeast Asian countries are suffering from similar air pollution problems. Thus, these countries should transform their economies in order to reduce pollution. In order to solve this gap between encouraging economic development and preventing environmental pollution mishaps, governments must develop a positive-sum game approach toward sustainable development. In this Special Issue, several papers conclude that an 
innovative way of thinking is at the core of sustainable development, because only innovation can enhance environmentally friendly efficiency and productivity without any conflict among the partners of public and private sectors [8]. The voluntary participation of the private sector may come from the value sharing with the new policies of government as well as market-oriented governance for the policies. The papers in this special issue examine the ideals good governance from the industry perspective. By the same token, to enhance the governance in terms of the consumer's perspective, cultural factors such as education and knowledge sharing must also be considered. Certainly, environmental education brings about the environmentally friendly principles as well as the voluntary commitment to sustainable governance. Education, as an investment in human capital, is regarded as an important determinant of sustainable economic growth [4].

The Chinese government has continuously made efforts to protect the ecological environment by cultural education. However, even if the government has played a leading role, it only has a limited regulatory effect due to the reluctant or hesitant attitudes of the private sector $[1,8]$. Policies can be divided into two categories-incentives for promotions and taxes or penalties for purposes of regulation. It is not easy to choose one of these directions, and a mixed policy may have a better performance. All of the papers in this Special Issue emphasize that differentiated policies may increase the feasibility of environmental policies $[4,9,10]$. This implies that the traditional approach with competition-based maximization is not effective anymore for the achievement of sustainable development, because harmonized value creation is important for all the stakeholders of environmentally friendly development. Value creation in network management is crucial for good governance, because it results in the proactive, voluntary participation of all the interest stakeholders and partners [8]. This is especially true in the case of the continuation of sustainable development based on the virtuous spiral circle over time. In general, innovation leads to technological development and thus may result in a reluctant attitude in people accustomed in the existing system. Therefore, governance is very important; if all the related parties are partners, they would be engaged to continuously participate in this virtuous spiral circle of innovation. This is the background for the core factor of network management among the stakeholders for sustainable development. Network management should be based on cooperative conditions and both the public and private sectors should be the partners in this network. In the following section, we focus on the effect of cooperation on network management to create value according to Asian perspectives [1].

\section{Regional Cooperation with PPPs}

Most Asian countries are experiencing escalating air pollution and other environmental challenges. Many political measures, such as regulations and promotional subsidies, have not proved effective or efficient due to a lack of governance. In many countries, the people tend to participate in oppositional activities against environmental policies. There have been many demonstrations against wind power facilities in Korea, for example. Most Korean people say, "it is good, but not in my backyard (NIMBY)". This because is because the technology is perceived as not giving any direct benefits, but only posing sacrifices for the public, such as loud noise, decreasing land or housing prices, etc. Therefore, a public private partnership (PPP) is not easily workable in this conflict of interest. In this situation, most private sector companies as well as the general population do not participate voluntarily in new challenges for sustainable development. This is because the policy itself is equally effective for all according to its the top-down approach. Therefore, this kind of equal treatment for all, including free riders, does result in the NIMBY phenomenon [1]. The people do not want to be treated as equal for all, because somebody is sacrificed with it, while others do not [9].

Nonetheless, differentiated polices should be harmonized to create value for all stakeholders. This environmental NIMBY phenomenon is seen in many countries; as such, it is apparent that a harmonized mixed policy is very important from the regional perspective to find solutions to the air pollution issues. As shown in Figure 1, every winter northeast Asian countries are suffering from severe air pollution in the form of smog, coming from the northwest direction [9]. Due to their 
geographical placement, there is always a strong cold wind from the northwest, blowing toward Korea and Japan, and this wind bring about the severe PM-related air pollution resulting from the heavy air pollution in northern China. Without this wind in the summer and autumn seasons, most air pollution in the region result from the internal sources such as transportation emissions. However, during the winter season, due to the strong wind, the region inevitably suffers from the heavily polluted wind from neighboring countries [10]. More than $50 \%$ of the air pollution comes from northern China in the winter season. In February of 2016, 67\% of air pollution came from northern China [10]. In particular, the northern part of China, consisting of Beijing-Tianjin-Hebei, occupies less than $3 \%$ of the land in China. Yet, the region contains $27 \%$ of charcoal electricity power generators, $30 \%$ of trucks heavier than 3.5 tons, and $43 \%$ of steel manufacturing factories in all of China [10]. Due to these top-polluting, energy-consuming industries in the region, all northeast Asian countries suffer from the same air pollution dilemma every year. In order to overcome this regional issue, the most important mission is to organize cooperative efforts among the different governments in the region. Regional cooperation could help create new innovative ways to overcome this winter dilemma by improving the network management of air pollution.

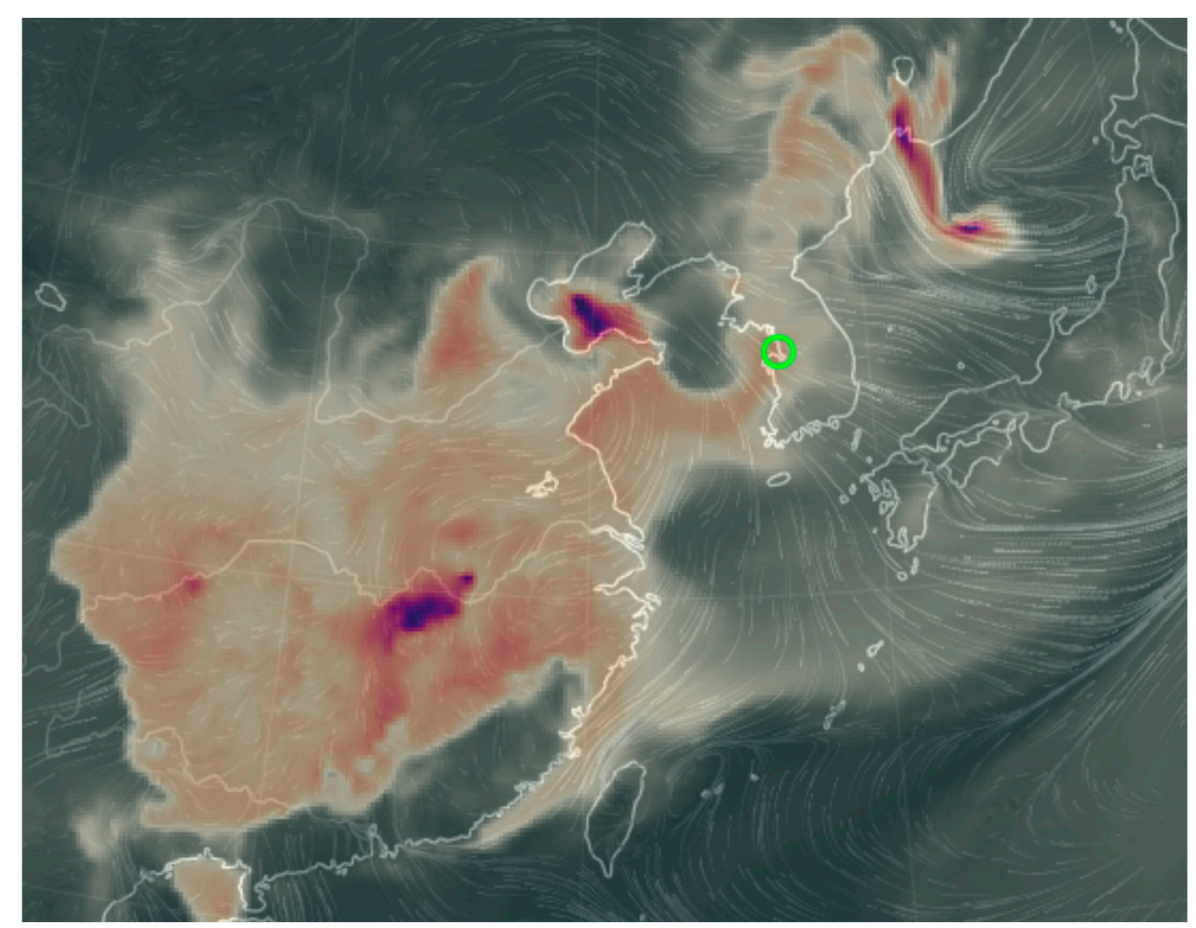

Figure 1. Regional movement of air pollution in the winter season. Available online: https: / / earth.nullschool.net/\#current/chem/surface/level/overlay=cosc/equirectangular= $121.95,35.41,925 /$ loc $=126.761,37.082$ (accessed on 20 February 2019).

Unfortunately, regional cooperation on issues of environmental protection or sustainable development is much more difficult than addressing similar issues on only a local scale, because the openness and partnership should be equitable for all member countries, resulting in loyalty to the specific field of cooperation among all participating countries [11]. Therefore, it is much more difficult to achieve sustainable governance in this regional cooperation network, even with strokes of innovation.

In general, mutual benefits and the creation of value sharing is essential for initial as well as continuous regional cooperation in global economic networks. In the initial stage, all the participating partners are excited by the expected value sharing, but if this is not realized quickly to the favor of all partners, it cannot be performed continuously, resulting in a lack of proactive participation. This kind of cooperation is much more important in northeast Asia. Even if one government came 
up with a great slogan and vision for all the countries, in reality, this could not promote the virtuous spiral of value creation and subsequent economic activities among the other partners [11]. The most outstanding problem in regional cooperation is the lack of servant leadership. Since sustainable development is based not on the maximization of the network manager's portion as the leading country, but on the harmonized value sharing through cooperative network management, all the regional cooperative projects across the countries' borders should be based on each member country's loyalty to this network [8].

In order to enhance the loyalty, all Asian countries employ the human network of guānxì (social relationship). Guānxì is one of the most important Asian values with a long historical background of unified ethnical ties. China, Korea, and Japan share the same cultural background steeped in this Asian value of guānxì. However, guānxì differs from the western style of social relationship or human network, since it advances step by step toward a higher level of social relationship from just a simple acquaintance in the psychological neighborhood, via stronger friendship among intimate and important persons, until the highest level of loyalty held by family members. In the initial stage of acquaintance, guānxì may eliminate initial practical and/or psychological barriers in a cooperative project. With the initial success as well as the equitable sharing of its performance, the second stage of guānxì may result in better commitment to an unpredictable mission. At the highest level of guānxì, all the members are ready to cooperate, innovate, and take responsibility for all. That is the ideal stage of PPP from a local perspective (as mentioned in Section 2) as well as from a regional perspective. Choi (2019) suggests an Asian model to create, maintain, and utilize the value of guānxi in a stepwise approach [1]. As shown in Figure 2, leading countries such as China should show their loyalty to all members and let them follow step by step on this optimal path toward sustainable development and regional cooperation in environmental issues, such as the heavily polluted winter wind in northeast Asia.

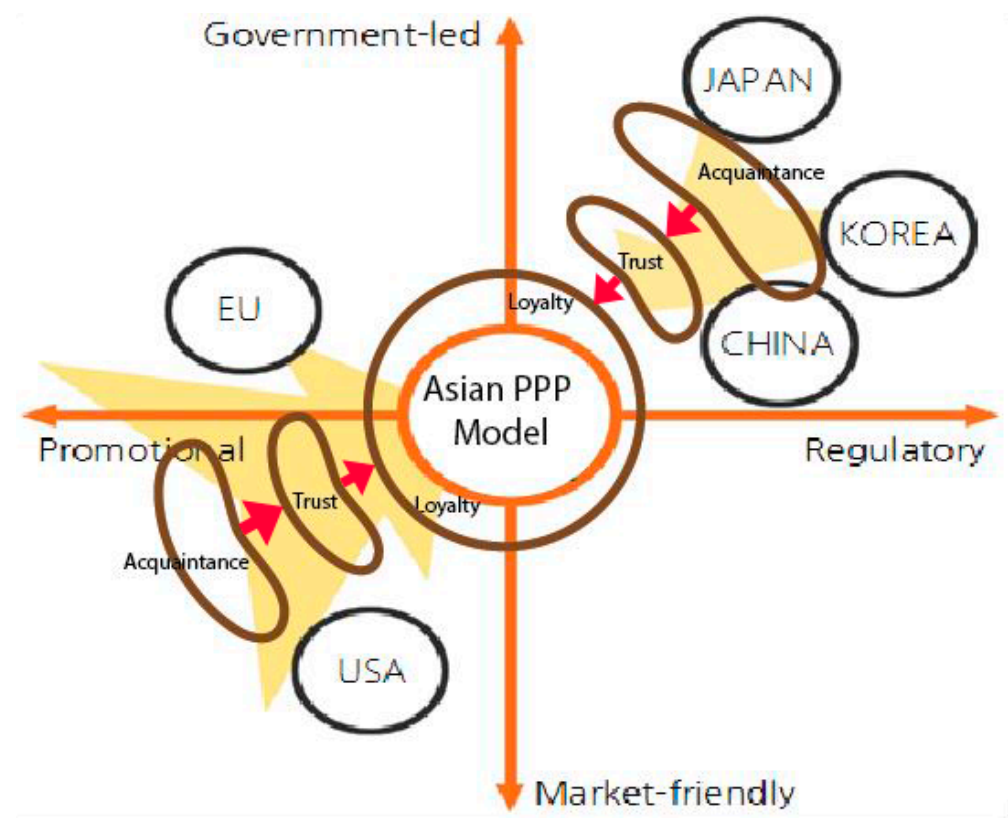

Figure 2. Stepwise guānxì approach toward the Asian public private partnership (PPP) model [1].

The sustainable governance-oriented approach is important for China, especially as a leading country in the region, to promote a cooperative positive-sum game for the purposes of regional sustainable development. In order to determine the optimal path by which to achieve sustainable governance, the neighboring countries should proactively create and share values in order to face future challenges. 


\section{Concluding Remarks}

At present, the northeast Asian region is presented with serious challenges coming from the ever-increasing air pollution dilemma. To make matters worse, there are serious conflicts surrounding China-USA trade negotiations, North Korean denuclearization issues, and historical and military conflicts between Korea and Japan. All these difficulties definitely require a positive-sum solution for all parties concerned. The most important mission should be to find a way to create value by harmonizing the interests of all parties concerned. Most of the papers in this Special Issue emphasize the importance of equitable, customized treatment for all partners, instead of top-down-based or regulatory equal measure policies. From a historical point of view, we learned that selfish dictatorships may lead the world toward a global economic war-as occurred during the Great Depression period initiated by the USA. Sustainable development may face sarcastic criticism from the internally competition-oriented industry side as well as external complaints from partner countries. In most of these challenges, the most important lesson from a cultural background may come from the Asian value of loyalty rooted in guānxì. Thus, we should cooperate to initiate, maintain, and utilize this important value with the workable mechanism of an Asian model for a harmonized PPP.

No government should be the leader with all other partners viewed simply as helpers, because this results in a lack of governance. For an ideal PPP, all the member countries should think they are leaders. All stakeholder members should not be passive helpers, but proactive partners to create value and share this value together. That is the spirit of the Asian model based on guānxì. Specifically, if one of the members such as China wants to be a leader, it should take the role of a servant leader for all. Nobody, including Chinese local residents as well as citizens of neighboring countries, should think they are object of the policy, but rather that they are the prosumers of that policy. Here, a prosumer is defined as a consumer as well as a producer of environmental policies. The government should listen to the views of the private sector and prepare customized policies for the public sector. If the private sector feels they can create value from a new policy, they will cooperate with it, and by their efforts they can and should share their portion of the participation reward in an appropriate manner. If this performance-oriented mechanism works well in the initial stage, then it will create the virtuous spiral cycle with much proactive participation of the private sector as a partner, resulting in sustainable governance. To determine this optimal path toward sustainable governance, the Sustainable Asia Conference had a 10th anniversary in 2018 at the Chinese Academy of Science in Beijing, and will continue its successful meeting with Special Issues in the coming year.

Funding: This research received no external funding.

Conflicts of Interest: The author declares no conflict of interest.

\section{References}

1. Choi, Y. The Asian Values of Guānxì as an Economic Model for Transition toward Green Growth. Sustainability 2018, 10, 2150. [CrossRef]

2. Choi, Y. Regional Cooperation for the Sustainable Development and Management in Northeast Asia. Sustainability 2018, 10, 548. [CrossRef]

3. Du, M.; Wang, B.; Zhang, N. National research funding and energy efficiency: Evidence from the National Science Foundation of China. Energy Policy 2018, 24, 335-346. [CrossRef]

4. Yu, Y.; Huang, J.; Zhang, N. Industrial eco-efficiency, regional disparity, and spatial convergence of China's regions. J. Clean. Prod. 2018. [CrossRef]

5. Guan, D.; Meng, J.; Reiner, D.; Zhang, N. Structural decline in China's $\mathrm{CO}_{2}$ emissions through transitions in industry and energy systems. Nat. Geosci. 2018. [CrossRef]

6. Newland, K. Migration as a factor in development and poverty reduction: The impact of rich countries' immigration policies on the prospects of the poor. In Impact of Rich Countries' Policies on Poor Countries; Routledge: Oxford, UK, 2017; pp. 187-213. 
7. Shuhong, W.; Sun, X.; Song, M. Environmental Regulation, Resource Misallocation, and Ecological Efficiency. Emerg. Mark. Financ. Trade 2019. [CrossRef]

8. Choi, Y. Digital Business and Sustainable Development: Asian Perspective; Routledge Publishing Co.: New York, NY, USA, 2017; p. 25.

9. Chen, J.; Wu, Y.; Xu, C.; Song, M. Global non-fossil fuel consumption: Driving factors, disparities, and trends. Manag. Decis. 2018. [CrossRef]

10. Choi, Y. Opinion: Majority of Korean Air Pollution Comes from China. Available online: http:/ / news.chosun.com/site/data/html_dir/2019/01/03/2019010303079.html?utm_source=naver\& utm_medium=original\&utm_campaign=news (accessed on 20 February 2019).

11. Feng, D.; Chen, Q.; Song, M.; Lianbiao, C. Relationship between the Degree of Internationalization and Performance in Manufacturing Enterprises of the Yangtze River Delta Region. Emerg. Mark. Financ. Trade 2019. [CrossRef] article distributed under the terms and conditions of the Creative Commons Attribution (CC BY) license (http://creativecommons.org/licenses/by/4.0/). 